\title{
Colorectal cancer screening, 2021: An update
}

\author{
The American Cancer Society now recommends screening for colorectal \\ cancer starting at age 45 years, not 50 . The best colorectal cancer \\ screening test is the one that the patient will complete. Colonoscopy and \\ the multitarget stool FIT-DNA test (Cologuard) are the screening tests most \\ likely to detect precancerous lesions and colorectal cancer.
}

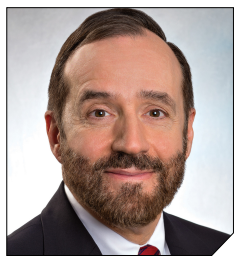

\section{Robert L. Barbieri, MD}

Chair Emeritus, Department of Obstetrics and Gynecology

Interim Chief, Obstetrics

Brigham and Women's Hospital

Kate Macy Ladd Distinguished Professor of Obstetrics,

Gynecology and Reproductive Biology

Harvard Medical School

Boston, Massachusetts

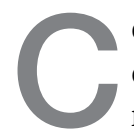

olorectal cancer is a common disease that has a very lengthy natural history of progression from small $(<8 \mathrm{~mm})$ to large $(\geq 8 \mathrm{~mm})$ polyps, then to dysplasia, and eventually to invasive cancer. It is estimated that this progression takes 10 years. ${ }^{1}$ The long natural history from preneoplasia to cancer makes colorectal cancer an ideal target for screening. Screening for colorectal cancer is divided into two clinical pathways, screening for people at average risk and for those at high risk. Clinical factors that increase the risk of colorectal cancer are listed in TABLE 1 (page 10). This editorial is focused on the clinical approach to screening for people at average risk for colorectal cancer.

\section{Colorectal cancer is the} second most common cause of cancer death The top 6 causes of cancer death in the United States are ${ }^{2}$ :

doi: 10.12788/obgm.0119
- lung cancer (23\% of cancer deaths)

- colon and rectum (9\%)

- pancreas (8\%)

- female breast (7\%)

- prostate $(5 \%)$

- liver/bile ducts (5\%).

In 2020 it is estimated that 147,950 people were diagnosed with colorectal cancer, including 17,930 people less than 50 years of age. ${ }^{3}$ In 2020 , it is also estimated that 53,200 people in the United States died of colorectal cancer, including 3,640 people younger than age $50 .{ }^{3}$ By contrast, the American Cancer Society estimates that, in 2021, cervical cancer will be diagnosed in 14,480 women and 4,290 women with the disease will die. ${ }^{4}$

According to a Centers for Disease Control and Prevention (CDC) study, among people 50 to 64 years of age, $63 \%$ report being up to date with colorectal cancer screening-leaving a full one-third not up to date with their screening. ${ }^{5}$ Among people aged 65 to $75,79 \%$ report being up to date with colorectal cancer screening. Among those aged 50 to 64 , those with health insurance were more likely to be up to date with screening than people without insurance-67\% versus $33 \%$, respectively. People with a household income greater than $\$ 75,000$ and less than $\$ 35,000$ reported up-to-date screening rates of $71 \%$ and $55 \%$, respectively. Among people aged 50 to 64 , non-Hispanic White and Black people reported similar rates of being up to date with colorectal screening ( $66 \%$ and $65 \%$, respectively). Hispanic people, however, reported a significantly lower rate of being up to date with colorectal cancer screening $(51 \%){ }^{5}$

A weakness of this CDC study is that the response rate from the surveyed population was less than $50 \%$, raising questions about validity and generalizability of the reported results. Of note, other studies report that Black men may have lower rates of colorectal cancer screening than non-Black men. ${ }^{6}$ These data show that focused interventions to improve colorectal cancer screening are required for people 
TABLE 1 Clinical factors associated with a higher risk of

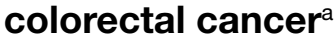

- Personal history of colorectal cancer

- Personal history of an adenomatous polyp

- Personal history of ulcerative colitis or Crohn disease

- Obesity

- Diabetes mellitus

- Exposure to abdominal radiation in childhood

- Family history of colorectal cancer or an advanced adenomatous polyp

- Biological family member with a genetic syndrome that is associated with colorectal cancer (eg, Familial adenomatous polyposis, Lynch syndrome, Juvenile polyposis syndrome, Peutz-Jeghers syndrome, MUTYH-associated polyposis)

- HIV infected men who have receptive sex with men (anal neoplasia risk)

- African ancestry (higher rate of disease before age 50 years)

aThis list is not inclusive of all factors associated with an increased risk of colorectal cancer

50 to 64 years of age, particularly among underinsured and some minority populations.

\section{Inequitable health outcomes for colorectal cancer}

The purpose of screening for cancer is to reduce the morbidity and mortality associated with the disease. Based on the Surveillance, Epidemiology and End Results (SEER) national reporting system, from 2014 to 2018 colorectal death rates per 100,000 adults were 18 for Black adults; 15.1 for American Indian/Alaska native adults; 13.6 for White non-Hispanic adults; 10.9 for White, Hispanic adults; and 9.4 for Asian/Pacific Islander adults. ${ }^{7}$ Lack of access to and a lower utilization rate of high-quality colon cancer screening modalities, for example colonoscopy, and a lower rate of optimal colon cancer treatment may account for the higher colorectal death rate among Black adults. ${ }^{8,9}$

\section{Colorectal cancer screening should begin at age 45}

In 2015 the Agency for Health Research and Quality (AHRQ) published data showing that the benefit of initiating screening for colorectal cancer at 45 years of age outweighed the additional cost. ${ }^{10}$ In 2018, the American Cancer Society recommended that screening for colorectal cancer should begin at age $45 .{ }^{11}$ In 2021, after resisting the change for many years, the US Preventive Services Task Force (USPSTF) also recommended that screening for colorectal cancer should begin at $45 .^{7}$ The new recommendation is based on statistical models that showed a significant increase in life-years gained at a small incremental cost. The USPSTF also recommended that clinicians and patients could consider discontinuing colorectal cancer screening at 75 years of age because the net benefit of continuing screening after age 75 is minimal.
Prior to 2021 the USPSTF recommended that screening be initiated at age 50. However, from 2010 to 2020 there was a significant increase in the percentage of new cases of colorectal cancer detected in people younger than 50. In 2010, colon and rectal cancer among people under 50 years of age accounted for $5 \%$ and $9 \%$ of all cases, respectively. ${ }^{12}$ In 2020 , colon and rectal cancer in people younger than age 50 accounted for $11 \%$ and $15 \%$ of all cases, respectively. ${ }^{3}$

\section{Options for colon cancer screening}

There are many options for colorectal cancer screening (TABLE 2). ${ }^{10,13}$ Experts conclude that the best colorectal cancer screening test is the test that the patient will complete. Among options for screening, colonoscopy and the multitarget stool FIT-DNA test (Cologuard) have greater sensitivity for detecting colorectal precancer and cancer lesions compared with fecal immunochemical testing (FIT), computed tomography colonography imaging (CTC), and stool guaiac testing (see TABLE 1).

In my practice, I suggest patients use either colonoscopy (every 10 years) or the multitarget stool FITDNA test (every 1 to 3 years) for screening. Most of my patients select colonoscopy, but some prefer the multitarget stool FIT-DNA test because they fear the pre-colonoscopy bowel preparation and the risk of bowel perforation with colonoscopy. Most colonoscopy procedures are performed with sedation, requiring an adult to take responsibility for transporting the patient to their residence, adding complexity to the performance of colonoscopy. These two tests are discussed in more detail below. 
TABLE 2 Estimated sensitivity and specificity of select screening tests for colorectal cancer $^{\mathrm{a}, 10,13}$

\begin{tabular}{|c|c|c|c|c|}
\hline Test & Test methodology & Test interval & Sensitivity & Specificity \\
\hline Colonoscopy & $\begin{array}{l}\text { Direct visualization and biopsy } \\
\text { of lesions; histologic analysis of } \\
\text { biopsied lesions }\end{array}$ & Every 10 years & $95 \%^{\mathrm{b}}$ & $\begin{array}{l}\text { Gold standard } \\
\text { test based on } \\
\text { histologic analysis } \\
\text { of biopsied tissue }\end{array}$ \\
\hline $\begin{array}{l}\text { Multitarget stool } \\
\text { FIT-DNA test }\end{array}$ & $\begin{array}{l}\text { Immunochemical detection of } \\
\text { hemoglobin plus DNAc testing } \\
\text { of stool; stool specimen sent to lab }\end{array}$ & Every 1 to 3 years & $92 \%$ & $90 \%$ \\
\hline $\begin{array}{l}\text { Computed tomography } \\
\text { (CT) colonography }\end{array}$ & $\begin{array}{l}\text { CT imaging of colon with computer } \\
\text { reconstruction of images }\end{array}$ & Every 5 years & $84 \%$ & $88 \%$ \\
\hline $\begin{array}{l}\text { Fecal immunochemical } \\
\text { test for heme (FIT) }\end{array}$ & $\begin{array}{l}\text { Immunochemical detection of } \\
\text { hemoglobin; stool specimen sent } \\
\text { to lab }\end{array}$ & Annual & $74 \%$ & $96 \%$ \\
\hline $\begin{array}{l}\text { Guaiac fecal occult } \\
\text { blood test }\end{array}$ & $\begin{array}{l}\text { Stool from } 3 \text { bowel movements is } \\
\text { smeared on } 3 \text { test cards; cards are } \\
\text { sent to a laboratory; stool should } \\
\text { not be collected during a rectal } \\
\text { examination }\end{array}$ & Annual & $70 \%$ & $93 \%$ \\
\hline $\begin{array}{l}\text { aSome estimates are extrapolate } \\
\text { 'Sensitivity of colonoscopy for d } \\
\text { "Multiple nucleic acid tests relev }\end{array}$ & $\begin{array}{l}\text { ased on sensitivity for detection of precancer } \\
\text { cting colorectal cancer are estimated from stu } \\
\text { to the development of colon cancer are perfo }\end{array}$ & $\begin{array}{l}\text { denomas. } \\
\text { where } 2 \text { colonoscopie }\end{array}$ & serformed in $\mathrm{s}$ & hort period of time. \\
\hline
\end{tabular}

\section{Colonoscopy}

Colonoscopy occupies a unique position among the options for colorectal cancer screening because it is both a screening test and the gold standard for diagnosis, based on histologic analysis of the polypoid tissue biopsied at the time of colonoscopy. For all other screening tests, if the test yields an abnormal result, it is necessary to perform a colonoscopy. Colonoscopy screening offers the advantage of "one and done for 10 years." In my practice it is much easier to manage a test that is performed every 10 years than a test that should be performed annually.

Colonoscopy also accounts for most of the harms of colorectal screening because of serious procedure complications, including bowel perforation ( 1 in 2,000 cases) and major bleeding ( 1 in 500 cases). ${ }^{7}$

\section{Multitarget stool FIT-DNA test (Cologuard)}

The multitarget stool FIT-DNA test is a remarkable innovation in cancer screening combining 3 independent biomarkers associated with precancerous lesions and colorectal cancer. ${ }^{14}$ The 3 test components include ${ }^{14}$ :

- a fecal immunochemical test (FIT) for hemoglobin (which uses antibodies to detect hemoglobin)

- a test for epigenetic changes in the methylation pattern of promoter DNA, including the promoter regions on the N-Myc Downstream-Regulated Gene 4 (NDRG4) and Bone Morphogenetic Protein 3 (BMP3) genes

- a test for 7 gene mutations in the V-Ki-ras2 Kirsten rat sarcoma viral oncogene homolog (KRAS).

In addition, the amount of the beta-actin DNA present in the stool specimen is assessed and used as a quantitative control for the total amount of DNA in the specimen. In one large clinical study, 9,989 people at average risk for colorectal cancer were screened with both a multitarget stool FIT-DNA test and a stool FIT test. $^{15}$ Positive test results triggered a referral for colonoscopy. Among this cohort, $1 \%$ of participants were diagnosed with colorectal cancer and $7.6 \%$ with a precancerous lesion. The sensitivity of the multitarget stool FITDNA test and the FIT test for detecting colorectal cancer was $92.3 \%$ and $73.8 \%$, respectively. The sensitivities of the multitarget stool FIT-DNA test and the FIT test for detecting precancerous lesions were $42.4 \%$ and $23.8 \%$, respectively. The specificity of the FIT-DNA and FIT tests for 
detecting any cancer or precancerous lesion was $90 \%$ and $96.4 \%$, respectively. ${ }^{15}$ The FIT test is less expensive than the multitarget stool FIT-DNA test. Eligible patients can order the FIT test through a Quest website. ${ }^{16}$ In June 2021 the published cost was $\$ 89$ for the test plus a $\$ 6$ physician fee. Most insurers will reimburse the expense of the test for eligible patients.

The multitarget stool FIT-DNA test should be performed every 1 to 3 years. Unlike colonoscopy or CT colonography, the stool is collected at home and sent to a testing labora- tory, saving the patient time and travel costs. A disadvantage of the test is that it is more expensive than FIT or guaiac testing. Eligible patients can request a test kit by completing a telemedicine visit through the Cologuard website. ${ }^{17}$ One website lists the cost of a Cologuard test at $\$ 599 .^{18}$ This test is eligible for reimbursement by most insurers.

\section{Ensure patients are informed of needed screening}

Most obstetrician-gynecologists have many women in their practice who are aged 45 to 64 , a key target group for colorectal cancer screening. The American Cancer Society and the USPSTF strongly recommend that people in this age range be screened for colorectal cancer. Given that one-third of people these ages have not been screened, obstetriciangynecologists can play an important role in reducing the health burden of the second most common cause of cancer death by ensuring that their patients are up to date with colorectal screening.

\section{References}

1. Winawer SJ, Fletcher RH, Miller L, et al. Colorectal cancer screening, clinical guidelines and rationale. Gastroenterology. 1997;112:594. doi: 10.1053/gast.1997.v112.agast970594.

2. Centers for Disease Control and Prevention website. An update on cancer deaths in the United States. https://www.cdc.gov/cancer/dcpc/research /update-on-cancer-deaths/index.htm. Accessed July 14, 2021.

3. Siegel RL, Miller KD, Goding SA, et al. Colorectal cancer statistics, 2020. CA Cancer J Clin 2020;70:145-164. doi: 10.3322/caac.21601.

4. American Cancer Society website. Key statistics for cervical cancer. https://www.cancer.org/can cer/cervical-cancer/about/key-statistics.html. Accessed July 14, 2021.

5. Joseph DA, King JB, Dowling NF, et al. Vital signs colorectal cancer screening test use, United States. Morb Mortal Wkly Rep. 2020;69:253-259.

6. Rogers $\mathrm{CR}$, Matthews $\mathrm{P}, \mathrm{Xu} \mathrm{L}$, et al. Interventions for increasing colorectal cancer screening uptake among African-American men: a systematic review and meta-analysis. PLoS One. 2020;15:e238354. doi: 10.1371/journal pone.0238354

7. US Preventive Services Task Force. Screening for colorectal cancer: US Preventive Services Task Force recommendation statement. JAMA. 2021;325:1965-1977. doi: 10.1001/jama.2021.6238.

8. Carethers JM, Doubeni CA. Causes of socio- economic disparities in colorectal cancer and intervention framework and strategies. Gastroenterology. 2020;158:354-367. doi: 10.1053/j.ga stro.2019.10.029.

9. Rutter $\mathrm{CM}$, Knudsen $\mathrm{AB}$, Lin JS, et al. Black and White differences in colorectal cancer screening and screening outcomes: a narrative review. Can cer Epidemiol Biomarkers Prev. 2021;30:3-12. doi: 10.1158/1055-9965.EPI-19-1537.

10. Zauber A, Knudsen A, Rutter CM, et al; Writing Committee of the Cancer Intervention and Surveillance Modeling Network (CISNET) Colorectal Cancer Working Group. Evaluating the benefits and harms of colorectal cancer screening strategies: a collaborative modeling approach. AHRQ Publication No. 14-05203-EF-2. Rockville, MD: Agency for Healthcare Research and Quality; October 2015. file:///C:/Users/loconnor/Down loads/cisnet-draft-modeling-report.pdf. Accessed July 15, 2021

11. American Cancer Society website. Cancer screening guidelines by age. https://www.cancer .org/healthy/find-cancer-early/screeningrecommendations-by-age.html\#40-49. Accessed July 15, 2021

12. Bailey CE, Hu CY, You YN, et al. Increasing disparities in the age-related incidences of colon and rectal cancers in the United States, 19752010. JAMA Surg. 2015;150:17-22. doi: 10.1001 /jamasurg.2014.1756.
13. Knudsen AB, Zauber AG, Rutter CM, et al. Estimation of benefits, burden, and harms of colorectal cancer screening strategies: modeling study for the US Preventive Services Task Force. JAMA 2016;315:2595. doi: 10.1001/jama.2016.6828.

14. FDA summary of safety and effectiveness data. https://www.accessdata.fda.gov/cdrh_docs /pdf13/P130017B.pdf. Accessed July 15, 2021.

15. Imperiale TF, Ransohoff DF, Itzkowitz $\mathrm{SH}$, et al. Mulitarget stool DNA testing for colorectal-cancer screening. N Engl J Med. 2014;370:1287-1297. doi: 10.1056/NEJMoal311194.

16. FIT colorectal cancer screening. Quest Diagnostics website. https://questdirect.questdiagnostics. com/products/fit-colorectal-cancer-screening /d41c67cb-a16d-4ad6-82b9-1a77d32daf41?utm source $=$ google\&utm medium $=$ cpc\&utm _campaign $=71700000081635378 \& u t m$ _content $=58700006943838348 \&$ utm _term=p62498361603\&gclsrc=aw.ds\&gclid=EAIaI QobChMIgZLq9NOI8QIVufvjBx0slQWPEAAYAiA AEgKHqfD_BwE. Accessed July 15, 2021.

17. Request Cologuard without leaving your home. Cologuard website. https://www.cologuard.com /how-to-get-cologuard?gclsrc=aw.ds\&gclid=EAIa IQobChMIgZLq9NOI8QIVufvjBx0slQWPEAAYASAAEgKHIfD_BwE. Accessed July 15, 2021.

18. Cologuard. Colonoscopy Assist website. https: //colonoscopyassist.com/Cologuard.html. Accessed July 15, 2021. 